\title{
Detection of a Frequent Restriction Fragment Length Polymorphism in the Human T Cell Antigen Receptor Beta Chain Locus
}

\section{A Potential Diagnostic Tool}

\author{
Nancy Berliner, Allan D. Duby, Cynthia C. Morton, Philip Leder, and J. G. Seidman
}

Department of Genetics, Harvard Medical School, Boston, Massachusetts 02115

\begin{abstract}
Abnormal $T$ cell function is a feature of a spectrum of inherited and acquired diseases. We have detected a frequent restriction fragment length polymorphism in the human $T$ cell antigen receptor $\beta$-chain locus that may aid in the analysis of these disorders. A study of a panel of 18 normal individuals, testing for the presence of the polymorphism, showed it to account for $36 \%$ of the alleles in that group. In view of the fact that the $T$ cell receptor $\beta$-chain locus has been mapped to chromosome 7 , and that the disease ataxia telangiectasia (AT) is associated both with abnormal $T$ cell function and with chromosomal abnormalities of the same region of chromosome 7 , we investigated the possibility that the polymorphism could demonstrate linkage of the $T$ cell receptor locus to the gene for that disease. We demonstrated that the mutation causing AT did not lie within the $\beta$-chain locus itself, and that there was preliminary evidence that the two loci were not closely linked. This polymorphism may provide a useful tool for the study of other genetic disorders associated with abnormalities of $T$ cell function, as well as disorders associated with inherited or acquired abnormalities of chromosome 7 .
\end{abstract}

\section{Introduction}

The complex immunologic repertoire of the $\mathrm{T}$ lymphocyte is still poorly understood. $T$ cell dysfunction is part of a wide range of abnormalities, from congenital immunodeficiency syndromes to acquired autoimmune diseases and infectious and neoplastic immune suppression. The recent cloning of the $\beta$-chain of the receptor on the surface of the T lymphocyte $(1,2)$ offers new opportunities to understand the early steps in antigen recognition by that cell and may offer insights into the mechanism of $T$ cell dysfunction in some of these disorders. In this study, we have defined a restriction fragment length polymorphism (RFLP) ${ }^{1}$ of the $\mathrm{T}$ cell receptor $\beta$-chain locus that might prove useful in the analysis of these diseases.

Address reprint requests to Dr. Berliner.

Received for publication 28 March 1985.

1. Abbreviations used in this paper: AT, ataxia telangiectasia; kb, kilobases; RFLP, restriction fragment length polymorphism.

J. Clin. Invest.

(c) The American Society for Clinical Investigation, Inc.

$0021-9738 / 85 / 09 / 1283 / 03 \quad \$ 1.00$

Volume 76, September 1985, 1283-1285
Minor or major mutations may change the recognition sites for restriction enzymes within a gene locus without changing the protein sequences encoded by the genes involved. These mutations persist as detectable polymorphisms on Southern blot analysis of genomic DNA. One can analyze the inheritance pattern of a given gene locus by the use of these RFLPs as markers for the gene locus in which they occur (3). This technique has been used to analyze and predict the occurrence of several heritable diseases, including sickle cell disease $(4,5)$, thalassemia (6), and Huntington's disease (7). We have detected an RFLP in the $T$ cell $\beta$-chain locus with which similar analyses may be performed. We have documented its frequent occurrence in a group of normal individuals. We then evaluated the possible relation of the RFLP, and by inference, the T cell receptor $\beta$ chain locus, to the disease ataxia telangiectasia (AT).

AT is an autosomal recessive disorder associated with multiple neurologic and immunologic defects. Patients become symptomatic at an early age, with progressive cerebellar ataxia, oculocutaneous telangiectasia, and immunodeficiency. The disease is associated with increased chromosomal breakage and rearrangement and a predisposition to the development of malignancy. It is almost uniformly fatal, with death usually due to chronic pulmonary infections or malignancy (8).

AT is of interest when studying the $\beta$-chain locus for two reasons. Firstly, it is associated with $\mathrm{T}$ cell dysfunction. Secondly, it is associated with a high frequency of chromosome 7 rearrangements $(9,10)$. The T cell $\beta$-chain locus has been localized to chromosome 7 by somatic cell hybrids $(11,12)$ and chromosomal in situ hybridization (13). Regional assignment has been controversial, but recent in situ hybridization indicates that the genes are located at $7 \mathrm{q} 32$ with a secondary region of related sequences seen at 7p15-21 (14). These are precisely the areas on chromosome 7 at which the rearrangements in AT are known to occur $(9,10)$. Studies of the chromosomal translocations in Burkitt's lymphoma, in which the $c-m y c$ oncogene is brought into association with the immunoglobulin loci (15), have provided a model for relating cytogenetic abnormalities to regions of the genome that may have pathogenetic significance in the development of disease. Consistent with this model, the observations in patients with $\mathrm{AT}$ raised the intriguing possibility that the mutation giving rise to AT might involve a gene within, or in close proximity to, the $\mathrm{T}$ cell receptor $\beta$-chain locus.

\section{Methods}

Lymphoblastoid cell lines from patients with AT and their families were obtained from the Institute for Medical Research (Camden, NJ). High molecular weight DNA was prepared from peripheral blood cells from 
normal individuals and from the lymphoblastoid cell lines from patients with AT and their families (16). DNA was digested with the restriction enzyme Bgl II, size fractionated by agarose gel electrophoresis, and transferred onto nitrocellulose paper by the method of Southern (17). Filters were hybridized overnight to a nick-translated, ${ }^{32} \mathrm{P}$-labeled probe from the second constant region of the $\mathrm{T}$ cell $\beta$-chain locus (Fig. $1 \mathrm{~A}$ ), and washed at $53^{\circ} \mathrm{C}$ in $0.1 \%$ sodium dodecyl sulfate and $0.015 \mathrm{M} \mathrm{NaCl}$ and $0.0015 \mathrm{M} \mathrm{Na}$ citrate before autoradiography.

\section{Results}

The organization of the $\beta$-chain locus is diagramed in Fig. $1 A$. The two constant region genes $(\mathrm{C} \beta 1$ and $\mathrm{C} \beta 2)$ are physically linked and lie $\sim 12$ kilobases $(\mathrm{kb})$ from one another $(18,19)$. The probe used to analyze genomic DNA was a $1.0-\mathrm{kb}$ Bgl IIBgl II fragment derived from $C \beta 2$ as demonstrated in the figure. The two constant region genes are highly homologous in the coding region; therefore, this fragment hybridizes equally to both genes. After the DNA was digested with Bgl II and filters were hybridized to this probe, there were two restriction fragments predicted. The first resulted from hybridization to $C \beta 1$ on a restriction fragment of $10 \mathrm{~kb}$; the second resulted from hybridization to $C \beta 2$ on a fragment of $1 \mathrm{~kb}$ corresponding to the length of the probe itself. The blot in Fig. $1 B$ demonstrates that, in some cases, three bands were seen. The third band is $11.5 \mathrm{~kb}$ in length and may be best explained by a polymorphism leading to the absence of the $\mathrm{Bgl}$ II site lying $1.5 \mathrm{~kb} 5^{\prime}$ of $\mathrm{C} \beta 2$. An R1Bgl II probe lying just $5^{\prime}$ to the first probe (Fig. 1) confirmed this mapping by hybridizing to a $1.5-\mathrm{kb}$ fragment in individuals showing the polymorphism. This band was absent in individuals lacking the polymorphism (data not shown). In several families, inheritance of the polymorphism occurred in a predictable Mendelian fashion (not shown).

Analysis of a panel of 18 normal individuals demonstrated that the polymorphism is a common one. As shown in Fig. 2,

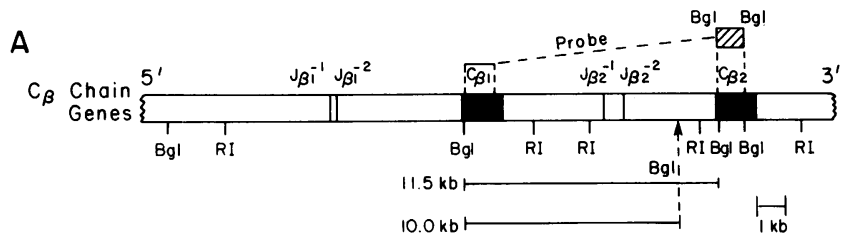

B

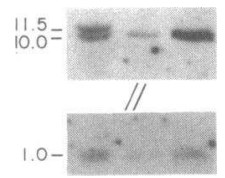

Figure 1. Organization of the human T cell receptor $\beta$-chain genes $(A)$ and detection of corresponding restriction fragments by Southern blot analysis $(B) .(A)$ The two constant region genes $(C \beta 1$ and $C \beta 2)$ are shown. Southern blot analysis was performed using a Bgl II-Bgl II probe from $C \beta 2$, which hybridizes equally to both constant regions. A putative polymorphic Bgl II site is indicated by the arrow, with a diagram of the predicted polymorphic restriction fragments of $10 \mathrm{~kb}$ and $11.5 \mathrm{~kb}$. (B) A representative Southern blot analysis demonstrates the Bgl II polymorphism. Bands are seen at $11.5 \mathrm{~kb}$ and $10 \mathrm{~kb}$ in lane 1 , indicating heterozygosity for the polymorphic Bgl II site, while a single band is seen at $10 \mathrm{~kb}$ in lanes 2 and 3, indicating homozygous presence of the polymorphic restriction enzyme site. The small band in all lanes indicates hybridization of the $\mathrm{Bgl} \mathrm{II-Bgl} \mathrm{II} \mathrm{probe} \mathrm{to} \mathrm{the} \mathrm{fragment}$ of DNA in C $\beta 2$ that corresponds to the probe itself.

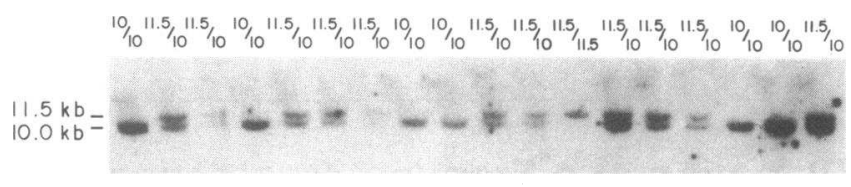

Figure 2. Analysis of the frequency of the Bgl II polymorphism in normal individuals. Southern blot analysis was performed using the previously described probe to investigate the occurrence of the RFLP in a panel of 18 normal individuals. Analysis reveals 6 individuals homozygous for the $10-\mathrm{kb}$ allele, 1 individual homozygous for the $11.5-\mathrm{kb}$ allele, and 11 individuals heterozygous for the two alleles.

23 of $36(64 \%)$ alleles lay on the shorter restriction fragment and 13 of $36(36 \%)$ lay on the longer fragment.

In view of the fact that the $\beta$-chain locus has been mapped to chromosome 7 , and that AT patients have been noted to have a high frequency of abnormalities in the same region of chromosome 7, we attempted to show linkage of the gene for AT to this locus. DNAs from patients with AT and their families were screened to find an informative distribution of the polymorphism. One family was found in which two parents heterozygous for the RFLP had a homozygous affected child. Analysis of that family revealed that AT did not segregate with the $\beta$-chain locus, as the patient had an unaffected sibling who was homozygous for the same allele (Fig. 3).

\section{Discussion}

We have described an RFLP in the T cell $\beta$-chain locus and documented its frequent occurrence in a group of normal individuals. We have used this polymorphism to analyze the inheritance pattern of the $\beta$-chain locus in an individual with AT and his family. By this means, we have shown that the inheritance of a particular $\beta$-chain locus genotype does not determine the inheritance of $\mathrm{AT}$.

RFLPs can be related to diseases caused by single gene defects in at least three ways. The mutation causing the disease may itself give rise to an altered restriction enzyme site. In such a case, the presence of the RFLP may be equated with presence of the mutant allele; it is seen only in carriers and affected individuals, and not in the general population. Alternatively, the RFLPs may arise within the locus of the gene of interest independently from the mutation that causes the disease. The RFLPs reflect common mutations associated with, but not responsible for, the less frequent mutations that alter gene expression and

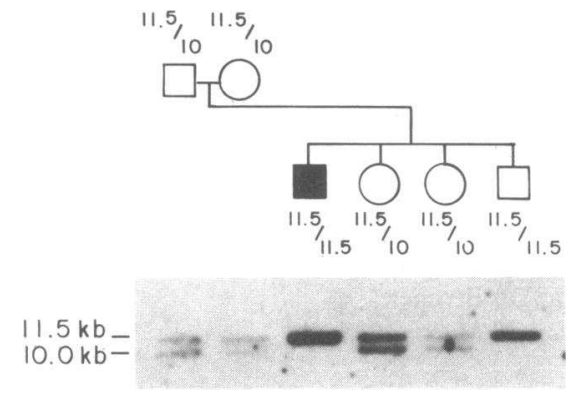

Figure 3. Analysis of the $\beta$-chain locus RFLP in a family with a child with AT. Southern blot analysis was performed on DNA derived from lymphoblastoid cell lines from a patient with AT and his family. Both parents are heterozygous for the Bgl II polymorphism, as are two unaffected children. The patient with AT is homozygous for the $11.5-\mathrm{kb}$ allele, as is one of his unaffected siblings. 
cause disease. Thus, the RFLP will not directly identify affected individuals in the general population but will be diagnostic in a family known to carry a mutant gene in association with a given RFLP. Finally, the RFLP may not lie within the locus of the gene of interest at all, but may lie close enough to the gene so that the two loci rarely, if ever, become separated by recombination. The diagnostic value of the RFLP then depends on statistical analysis of the proximity of the two genes.

In our analysis of a single family, we identified both an affected and an unaffected child who inherited the same $T$ cell $\beta$ chain locus alleles from their parents. This demonstrates that, at least in this family, the gene for AT does not lie within the T cell $\beta$-chain locus itself. We have not absolutely excluded the possibility that the two loci are linked by the third way described above. One family is insufficient to make this determination. The two genes may be linked, with recombination having occurred in this family. The fact that in one of four offspring in a single pedigree the genes for AT and the two $\beta$-chain alleles segregate independently merely suggests that the two loci are probably not tightly linked. AT is also an extremely heterogeneous disease, and it is possible that in other pedigrees with a different genotypic abnormality the gene may be shown to be related to the $\beta$-chain locus.

Although we have not shown linkage of the RFLP to the locus for the disease AT, the polymorphism we have described should prove useful in analyzing other phenomena related to $T$ cell function and dysfunction. The T cell receptor $\beta$-chain locus undergoes rearrangement in a manner analogous to the immunoglobulin heavy chain locus (20). This and the evidence that chromosome 7 rearrangements occasionally occur in the same region in short-term lymphocyte cultures of normal individuals (21) suggest that the locus lies in a region of the genome that undergoes active recombination. Again using the immunoglobulin locus as a model, this functional recombinant activity may also give rise to aberrant and dysfunctional rearrangements. It seems likely that the polymorphism will prove useful in the analysis of other disorders associated with inherited or acquired abnormalities of this region of the genome.

\section{Acknowledgments}

We acknowledge support from E. I. Du Pont de Nemours \& Co., Inc.,/ Sorvall Instruments Div., Newton, CT, and the American Business Cancer Research Foundation.

Dr. Berliner is supported by Public Health Service grant 1 K08 CA00977-01. Dr. Duby is supported by a fellowship from the Medical Research Council of Canada and a Career Development Award from the Arthritis Society of Canada. Dr. Morton is supported by National Institutes of Health postdoctoral fellowship CA-07511. Dr. Seidman is the recipient of National Institutes of Health grants AI-19438 and AI18436, as well as a grant from the Mallinkrodt Foundation.

\section{References}

1. Yanagi, Y., Y. Yoshikai, K. Leggett, S. P. Clark, I. Aleksander, and T. W. Mak. 1984. A human T cell-specific cDNA clone encodes a protein having extensive homology to immunoglobulin chains. Nature (Lond.). 308:145-149.

2. Hedrick, S. M., D. I. Cohen, E. A. Nielsen, and M. M. Davis. 1984. Isolation of cDNA clones encoding $T$ cell-specific membrane-associated proteins. Nature (Lond.). 308:149-153.

3. Botstein, D., R. L. White, M. Skolnick, and R. Davis. 1980. Construction of a genetic linkage map in man using restriction fragment length polymorphisms. Am. J. Hum. Genet. 32:314-331.

4. Kan, Y. W., and A. M. Dozy. 1978. Polymorphism of DNA se- quence adjacent to human $\beta$-globin structural gene: relationship to sickle mutation. Proc. Natl. Acad. Sci. USA. 75:5631-5635.

5. Chang, J. C., and Y. W. Kan. 1982. A sensitive new prenatal test for sickle-cell anemia. N. Engl. J. Med. 307:30-32.

6. Orkin, S. H., H. H. Kazazian, Jr., S. E. Antonarakis, S. C. Goff, C. D. Boehm, J. P. Sexton, P. G. Waber, and P. J. V. Giardina. 1982. Linkage of $\beta$-thalassemia mutations and $\beta$-globin gene polymorphisms in human $\beta$-globin gene cluster. Nature (Lond.). 296:627-631.

7. Gusella, J. F., N. S. Wexler, P. M. Conneally, S. L. Naylor, M. A. Anderson, R. E. Tanzi, P. C. Watkins, K. Ottina, M. R. Wallace, A. Y. Sakaguchi, A. B. Young, I. Shoulson, E. Bonilla, and J. B. Martin. 1983. A polymorphic DNA marker genetically linked to Huntington's disease. Nature (Lond.). 306:234-238.

8. Waldmann, T. A. 1983. Ataxia telangiectasia: a multisystem hereditary disease with immunodeficiency, impaired organ maturation, Xray hypersensitivity, and a high incidence of neoplasia. Ann. Intern. Med. 99:367-379.

9. Aurias, A., B. Dutrillaux, D. Buriot, and J. Lejeune. 1980. High frequencies of inversions and translocations of chromosomes 7 and 14 in ataxia telangiectasia. Mutat. Res. 69:369-374.

10. O'Connor, R. D., M. G. Brown, and U. Francke. 1982. Immunologic and karyotypic studies in ataxia-telangiectasia; specificity of break points on chromosomes 7 and 14 in lymphocytes from patients and relatives. In Ataxia-Telangiectasia-A Cellular and Molecular Link between Cancer, Neuropathology and Immune Deficiency. B. A. Bridges and D. G. Harnden, editors. John Wiley and Sons, Ltd., New York. 259-270.

11. Collins, M. K. L., P. N. Goodfellow, M. J. Dunne, N. K. Spurr, E. Solomon, and M. J. Owen. 1984. The human T-cell antigen receptor $\beta$ chain gene maps to chromosome 7. EMBO (Eur. Mol. Biol. Organ.) J. 3:2347-2349.

12. Barker, P. E., F. H. Ruddle, H. Royer, O. Acuto, and E. L. Reinherz. 1984. Chromsomal localization of human T-cell receptor gene Tiß. Science (Wash. DC). 226:348-349.

13. Caccia, N., M. Kronenberg, D. Saxe, R. Haars, G. A. P. Bruns, J. Goverman, M. Malissen, H. Willard, Y. Yoshikai, M. Simon, L. Hood, and T. W. Mak. 1984. The T cell receptor $\beta$ chain genes are located on chromosome 6 in mice and chromosome 7 in humans. Cell. 37:10911099.

14. Morton, C. C., A. D. Duby, R. L. Eddy, T. B. Shows, and J. G. Seidman. 1985. Genes for $\beta$ chain of human T-cell antigen receptor map to regions of chromosomal rearrangement in T cells. Science (Wash. DC). 228:582-585.

15. Taub, R., I. Kirsch, C. Morton, G. Lenoir, D. Swan, S. Tronick, S. Aaronson, and P. Leder. 1982. Translocation of the $c-m y c$ gene into the immunoglobulin heavy chain locus in human Burkitt lymphoma and murine plasmacytoma cells. Proc. Natl. Acad. Sci. USA. 79:78377841.

16. Bell, G. I., J. H. Karam, and W. J. Rutter. 1981. Polymorphic DNA region adjacent to the $5^{\prime}$ end of the human insulin gene. Proc. Natl. Acad. Sci. USA. 78:5750-5763.

17. Southern, E. M. 1975. Detection of specific sequences among DNA fragments separated by gel electrophoresis. J. Mol. Biol. 98:503517.

18. Sims, J. E., A. Tunnacliffe, W. J. Smith, and T. H. Rabbits. 1984. Complexity of human T-cell antigen receptor $\beta$-chain constant- and variable-region genes. Nature (Lond.). 312:541-545.

19. Duby, A. D., K. A. Klein, C. Murre, and J. G. Seidman. 1985. A novel mechanism of somatic rearrangement predicted by a human $\mathrm{T}$ cell antigen receptor $\beta$-chain complementary DNA. Science (Wash. DC). 228:1204-1206.

20. Siu, G., S. P. Clark, Y. Yoshikai, M. Malissen, Y. Yanagi, E. Strauss, T. W. Mak, and L. Hood. 1984. The human T cell antigen receptor is encoded by variable, diversity, and joining gene segments that rearrange to generate a complete $\mathrm{V}$ gene. Cell. 37:393-402.

21. Ayme, S., J. F. Mattei, M. G. Mattei, Y. Aurran, and F. Giraud. 1976. Nonrandom distribution of chromosome breaks in cultured lymphocytes of normal subjects. Hum. Genet. 31:161-175. 